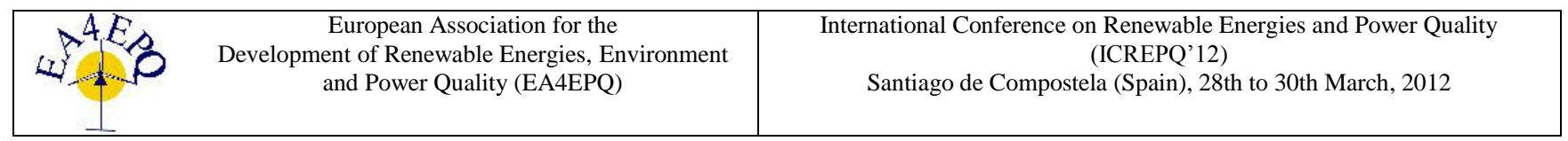

\title{
A Matrix converter-interfaced PM Generator System with Active Filtering Capabilities
}

\author{
N. Holtsmark, M. Molinas \\ Department of Electric Power Engineering \\ Norwegian University of Science and Technology \\ Trondheim, Norway \\ Phone/Fax number: +47 73594228, e-mail: \{Nathalie.Holtsmark; Marta.Molinas\}@ntnu.no
}

\begin{abstract}
In this paper is presented a matrix converterinterfaced Permanent Magnet (PM) generator system which can provide shunt active filtering in addition to converting and transferring energy. The modulation technique is the simple and well-known indirect space vector modulation. The filtering current injected by the matrix converter and the input filter capacitor voltage are controlled by cascaded proportional control loops. Results showing that the matrix converter successfully provides active power filtering are given. Simulations also indicate that the filtering capability of the system depends on the generator side power factor. An explanation to this effect is given.
\end{abstract}

\section{Key words}

Active power filter, matrix converter, converter control.

\section{Introduction}

A shunt Active Power Filter (APF) is a power converter that is controlled such as to produce a current that will compensate in real time some measured and undesired current components in the grid [1]. A typical system is shown in figure 1 . The shunt APF measures the load current $i_{\text {load }}$ and identifies some undesired harmonic or reactive current components. The shunt APF will then synthesize and inject a current $i_{m c}$ that contains those components. The harmonic and reactive components of the load current are then compensated leaving the source current $i_{\text {source }}$ to be sinusoidal and the power factor to be close to unity. Most shunt APF are today dedicated circuits that are composed of a Voltage Source Converter (VSC), a DC capacitor and an input filter inductance. However it is also possible to use grid connected adjustable speed drives with active front ends instead of diode rectifiers, to provide harmonic and reactive filtering services [2] in addition to controlling a load.

The matrix converter is emerging as an interesting alternative to the traditional back-to-back converter in applications where a small volume and weight and a high

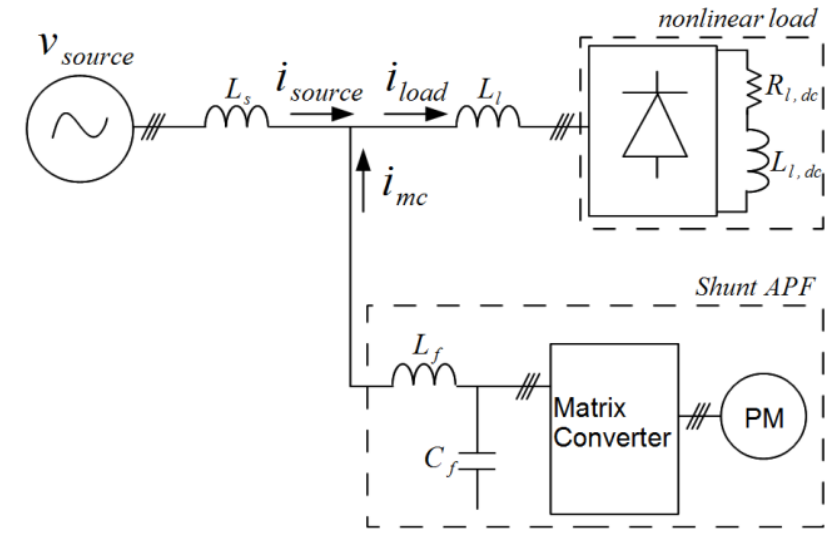

Fig. 1 Matrix converter-interfaced PM generator connected to a grid with reactive power and harmonic producing load.

reliability are important qualities, mainly because the matrix converter does not contain any bulky DC link capacitor.

As of today there has not been much discussion on the possible use of matrix converter for active filtering in the literature. One exception however is reference [3], where it was suggested to use the matrix converter interfacing a PM generator to provide active filtering. Such system could be useful in wind turbine or fuel engine generator systems where matrix converters are employed.

In [3] an indirect triangular carrier-based modulation is used as well as active damping to avoid resonance in the input LC filter. In this paper it is suggested to use indirect space vector modulation and simple proportional control for the input current and capacitor voltage as in [4].

The paper is organized as follows: Following the introduction, the second section presents the matrix converter and the indirect space vector modulation. The third section describes the control strategy of the current injected into the grid by the matrix converter and the filter capacitor voltage. In section four results from the simulation study are reported and discussed. Finally concluding remarks end the paper. 


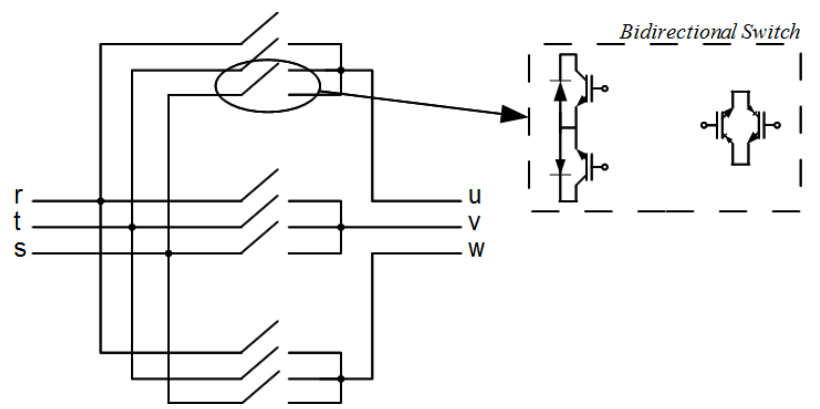

Fig. 2 The matrix converter and bidirectional switch.

\section{Matrix converter and modulation}

\section{A. The Matrix Converter}

The matrix converter is a direct AC-AC converter composed of nine bidirectional switches, see figure 2 . Unlike the conventional back-to-back converter it does not require a bulky DC link capacitor, saving volume and possibly increasing the lifetime of the converter [5]. However a LC filter is required at the input of the matrix converter as shown in figure 1 to filter out the harmonics at the switching frequency.

The bidirectional switch can be implemented either with two IGBTs and two diodes connected in antiparallel (left switch in figure 2) or two antiparallel Reverse-Blocking (RB) IGBTs (right switch in figure 2). The use of RBIGBTs can increase the efficiency of the matrix converter as there is only one semi-conductor device in the current path, thus reducing the conduction losses.

\section{B. Indirect Space Vector Modulation}

The indirect space vector modulation is a well-known modulation technique that outputs 12 gating signals as if it was providing the twelve switches of an indirect matrix converter (IMC), see figure 3; six signals to the switches of the Voltage Source Inverter (VSI) part, right part of the converter in figure 3 and six signals to the switches of the Current Source Rectifier (CSR) part, left part of the converter. With a logic circuit the 12 signals will be combined into 9 signals to provide for the real matrix converter switches. This modulation strategy makes it possible to separate the output voltage and input current control.

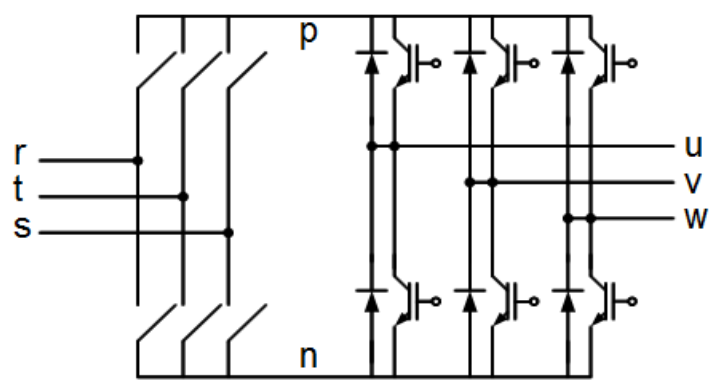

Fig. 3 The indirect matrix converter.
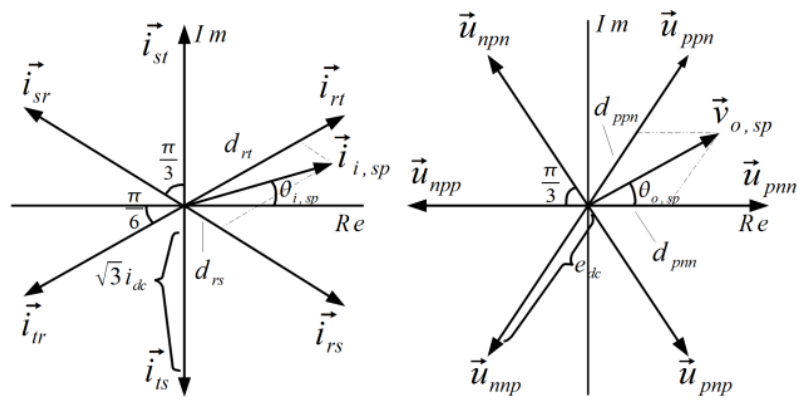

a)

b)

Fig. 4 The indirect space vector modulation.

The duty ratios for the VSI are calculated as follows for the first sector:

$$
\begin{aligned}
& d_{p n n}=\frac{2}{\sqrt{3}} \frac{\hat{V}_{\text {out }} \sin \left(\frac{\pi}{3}-\theta_{o, s p}\right)}{\hat{V}_{i n} \cos \Theta_{i n}} \cos \theta_{i, s p} \\
& d_{p p n}=\frac{2}{\sqrt{3}} \frac{\hat{V}_{o u t} \sin \left(\theta_{o, s p}\right)}{\hat{V}_{i n} \cos \Theta_{i n}} \cos \theta_{i, s p}
\end{aligned}
$$

With $\hat{V}_{\text {in }}$ and $\hat{V}_{\text {out }}$ the amplitude of respectively the input and output voltage and $\Theta_{i n}$ the input displacement angle. The duty ratios for the CSR are calculated as follows for the first sector:

$$
\begin{aligned}
& d_{r s}=\sin \left(\frac{\pi}{3}-\left(\theta_{i, s p}+\frac{\pi}{6}\right)\right) \frac{1}{\cos \theta_{i, s p}} \\
& d_{r t}=\sin \left(\theta_{i, s p}+\frac{\pi}{6}\right) \frac{1}{\cos \theta_{i, s p}}
\end{aligned}
$$

The duty ratios for the remaining sectors can be found by rotating the angle back to the first sector.

Finally the 12 signal for the IMC are converted to 9 signals for the direct matrix converter, by equating the transformation matrix for the direct matrix converter in eq. (5), and for the IMC in eq. (6). The signal are denoted

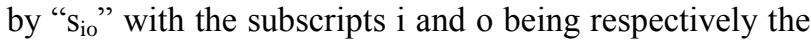
input and output to which the corresponding switch is connected.

$$
\begin{aligned}
& {\left[\begin{array}{l}
v_{u} \\
v_{v} \\
v_{w}
\end{array}\right]=\left[\begin{array}{lll}
s_{r u} & s_{s u} & s_{t u} \\
s_{v} & s_{s v} & s_{t v} \\
s_{r w} & s_{s w} & s_{t w}
\end{array}\right] \cdot\left[\begin{array}{l}
v_{r} \\
v_{s} \\
v_{t}
\end{array}\right]} \\
& {\left[\begin{array}{l}
v_{u} \\
v_{v} \\
v_{w}
\end{array}\right]=\left[\begin{array}{ll}
s_{u p} & s_{u n} \\
s_{v p} & s_{v n} \\
s_{w p} & s_{w n}
\end{array}\right] \cdot\left[\begin{array}{lll}
s_{r p} & s_{s p} & s_{t p} \\
s_{m} & s_{s n} & s_{t n}
\end{array}\right] \cdot\left[\begin{array}{l}
v_{r} \\
v_{s} \\
v_{t}
\end{array}\right]} \\
& {\left[\begin{array}{lll}
s_{r u} & s_{s u} & s_{t u} \\
s_{v v} & s_{s v} & s_{t v} \\
s_{r w} & s_{s w} & s_{t w}
\end{array}\right]=\left[\begin{array}{lll}
s_{u p} s_{r p}+s_{u n} s_{m} & s_{u p} s_{s p}+s_{u n} s_{s n} & s_{u p} s_{t p}+s_{u n} s_{t n} \\
s_{v p} s_{r p}+s_{v n} s_{m} & s_{v p} s_{s p}+s_{v n} s_{s n} & s_{v p} s_{t p}+s_{v n} s_{t n} \\
s_{w p} s_{r p}+s_{w n} s_{m} & s_{w p} s_{s p}+s_{w n} s_{s n} & s_{w p} s_{t p}+s_{w n} s_{t n}
\end{array}\right]}
\end{aligned}
$$

According to eq. (7), the signals of the IMC are transformed into signal for the direct converter with a logic circuit with OR corresponding to the sum and AND to the multiplication. 


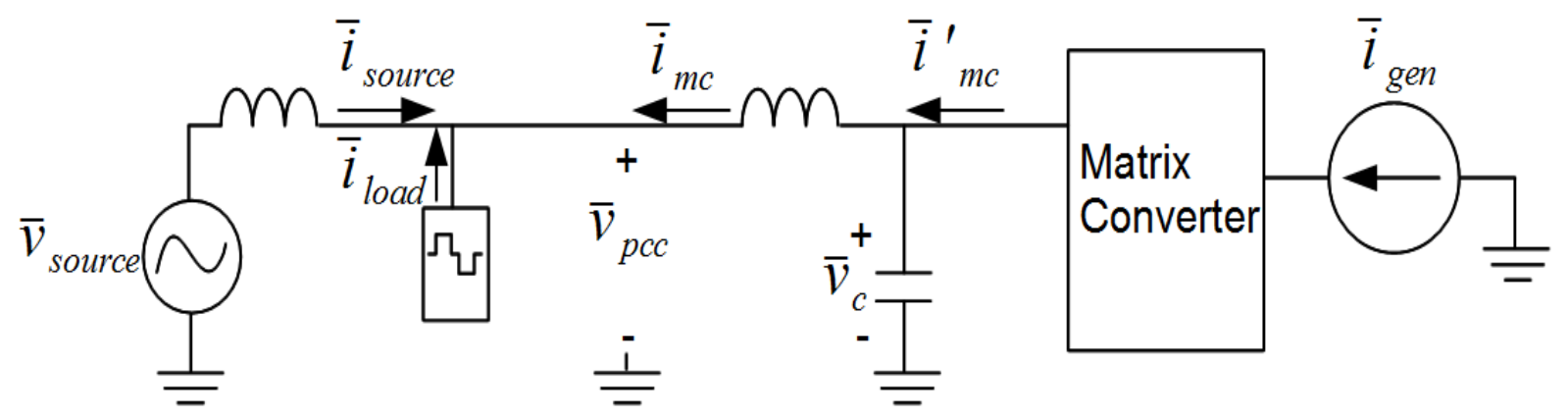

Fig. 5 Per phase equivalent of the system.

\section{Control Strategy}

A per-phase equivalent circuit of the considered system is depicted in figure 5 . The notation $\bar{x}$ indicates a vector containing the three phases "abc". In this paper, the PM generator was simply modeled by a current source and the focus was put on the control of the input current for the active filtering function.

The control strategy feature two cascaded control loops. The inner loop controls the capacitor voltage, $\bar{v}_{c}$, and provides the current reference $\bar{i}_{m c}^{\prime}$ to the modulation block of the matrix converter. The outer loop controls the current, $\bar{i}_{m c}$, injected into the grid at the PCC and provides the capacitor voltage $\bar{v}_{c}$ reference to the inner loop [4].

\section{A. Current reference}

In this section will be explained how to compute the current reference to provide the outer control loop. The load current is measured and transformed from the fixed abc-reference frame to the rotating dq-reference frame using relation (5) and the angle of the voltage at the Point of Common Coupling (PCC).

$\left[\begin{array}{l}x_{d} \\ x_{q}\end{array}\right]=\frac{2}{3}\left[\begin{array}{c}\cos \theta \\ \cos \left(\theta-\frac{2 \pi}{3}\right) \cos \left(\theta+\frac{2 \pi}{3}\right) \\ \sin \theta \sin \left(\theta-\frac{2 \pi}{3}\right) \sin \left(\theta+\frac{2 \pi}{3}\right)\end{array}\right]\left[\begin{array}{l}x_{a} \\ x_{b} \\ x_{c}\end{array}\right]$

Since the rotating dq-reference frame is based on the angle of the voltage at the PCC, the $\mathrm{d}$ and $\mathrm{q}$ load current components represent respectively the active and reactive components of the load current. The control objective is to compensate all the load current components except for the fundamental active load current component. Therefore a High Pass Filter (HPF) is introduced to filter out the fundamental component of the active current. Only the harmonic and reactive components remain in the current reference, see figure 6 .

The active current that is produced by the generator also needs to be added to the active current reference as the matrix converter also needs to transmit the active power produced by the generator. Finally are obtained the references $i_{m c, d}^{*}$ and $i_{m c, q}^{*}$ which are provided to the outer current control loop. All entities marked with asterisk are reference values as opposed to real/measured values.

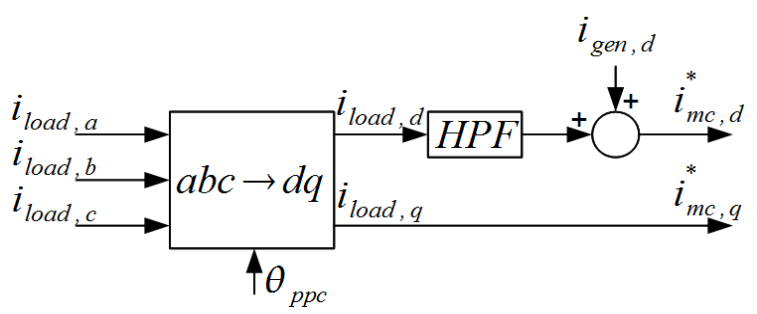

Fig. 6 Block diagram for calculation of current references

$$
i_{m c, d}^{*} \text { and } i_{m c, q}^{*} \text {. }
$$

\section{B. Current control}

The previous section explained how to calculate the current references. To control the current we use eq. (6) obtained from figure 5 :

$L_{f} \frac{d}{d t} \bar{i}_{m c}=\bar{v}_{p c c}-\bar{v}_{c}$

When eq. (6) is converted into the rotating dq-reference frame, cross-coupling terms appear as shown in eq. (7) which must be compensated.

$L_{f} \frac{d}{d t}\left[\begin{array}{l}i_{m c, d} \\ i_{m c, q}\end{array}\right]=\left[\begin{array}{c}v_{p c c} \\ 0\end{array}\right]-\left[\begin{array}{l}v_{c, d} \\ v_{c, q}\end{array}\right]-\omega L_{f}\left[\begin{array}{c}-i_{m c, q} \\ i_{m c, d}\end{array}\right]$

Eq. (7) in block diagram form is represented in figure 7. Simple proportional control can be used because of the integral effect of the inductor on the current.

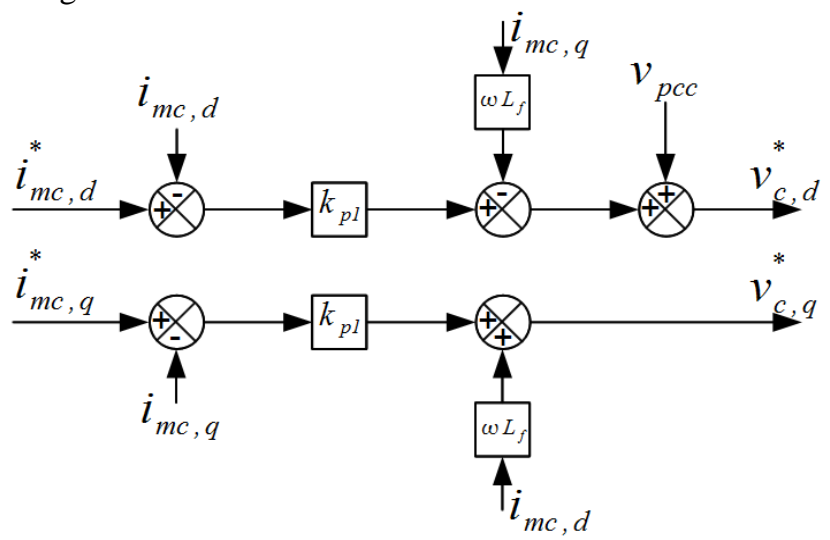

Fig. 7 Block diagram of current control. 


\section{Capacitor voltage control}

From figure 5 again we obtain eq. (8):

$C_{f} \frac{d}{d t} \bar{v}_{c}=\bar{i}_{m c}^{\prime}-\bar{i}_{m c}$

When transforming to the rotating dq-reference frame, again cross-coupling terms appear:

$C_{f} \frac{d}{d t}\left[\begin{array}{l}v_{c_{-} d} \\ v_{c_{-} q}\end{array}\right]=\left[\begin{array}{l}i_{m c, d}^{\prime} \\ i_{m c, q}^{\prime}\end{array}\right]-\left[\begin{array}{l}i_{m c, d} \\ i_{m c, q}\end{array}\right]-\omega C_{f}\left[\begin{array}{c}-v_{c, q} \\ v_{c, d}\end{array}\right]$

Eq. (9) in block diagram form is represented in figure 8 . Again simple proportional control can be used because of the integral effect of the filter capacitor on the voltage. Finally the matrix converter current reference are converted back from the dq-reference frame to the abcreference frame and fed to the modulation unit of the matrix converter.

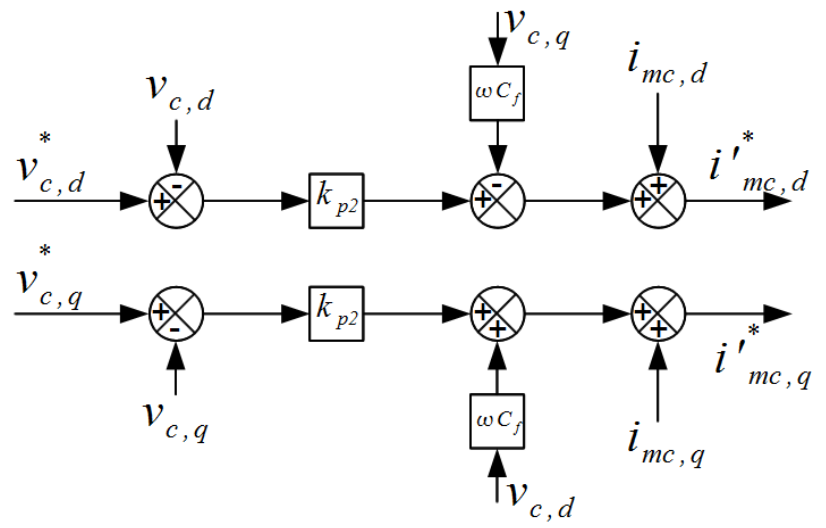

Fig. 8 Block diagram of capacitor voltage control.

\section{Simulation Results}

The simulation model of the system depicted in figure 1 was built in PSIM ${ }^{\circledR}$. The simulation parameters used are gathered in table I and are kept identical for all simulations.

For this simulation case suitable gains for the proportional control were found by trial and error with the consideration however that the inner loop should have a bandwidth one order of magnitude larger than the outer control loop. Thus the outer current control loop gain was set to $\mathrm{k}_{\mathrm{p} 1}=10$ and the inner voltage control loop gain to ten times $\mathrm{k}_{\mathrm{p} 1}$, that is $\mathrm{k}_{\mathrm{p} 2}=100$.

The first simulation is run for the matrix converter transferring active power amounting to $25 \%$ of the nonlinear load active power. The power factor on the generator side is set to 1 for the first simulation. The obtained curves of the load current, matrix converter and source current are depicted in figure 9. It is clear from figure 10 that the current injected by the matrix converter compensates partly the harmonics and reactive power of the nonlinear load. The THD of the source current is reduced from $27 \%$ to $11.4 \%$.

In figure 10 is shown the harmonic analysis of the load, matrix converter and source current. It can be seen that the matrix converter synthesizes a current that contains the same harmonics as the load. When injected into the grid the harmonics will cancel out the load current harmonics. As a result the source current displays reduced harmonic components. It is also possible to see from figure 10 that there is a small increase of harmonics around $750 \mathrm{~Hz}$ This corresponds to the resonance frequency of the filter capacitor and inductor and grid inductor. However the controller is able to limit the importance of resonance.

Table I. - Simulation Parameters

\begin{tabular}{|l|c|}
\hline \multicolumn{1}{|c|}{ PARAMETER } & VALUE \\
\hline $\mathrm{V}_{\text {source }}$ & $200\left[\mathrm{~V}_{\text {line-line, rms }}\right]$ \\
\hline $\mathrm{L}_{\mathrm{s}}$ & $2[\mathrm{mH}]$ \\
\hline $\mathrm{P}_{\text {nonlinear_load }}$ & $1[\mathrm{~kW}]$ \\
\hline $\mathrm{L}_{\mathrm{l}}$ & $2[\mathrm{mH}]$ \\
\hline $\mathrm{R}_{\mathrm{l}, \mathrm{dc}}$ & $75[\Omega]$ \\
\hline $\mathrm{L}_{\mathrm{l}, \mathrm{dc}}$ & $200[\mathrm{mH}]$ \\
\hline $\mathrm{C}_{\mathrm{f}}$ & $20[\mu \mathrm{HF}]$ \\
\hline $\mathrm{L}_{\mathrm{f}}$ & $0.5[\mathrm{mH}]$ \\
\hline $\mathrm{f}_{\text {switching }}$ & $20[\mathrm{kHz}]$ \\
\hline
\end{tabular}
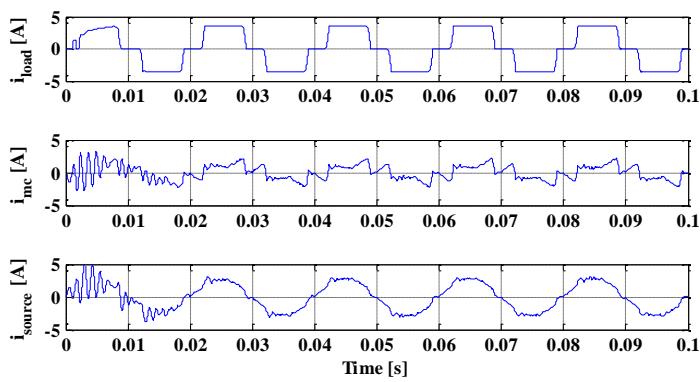

Fig. 9 Load, matrix converter and source currents.
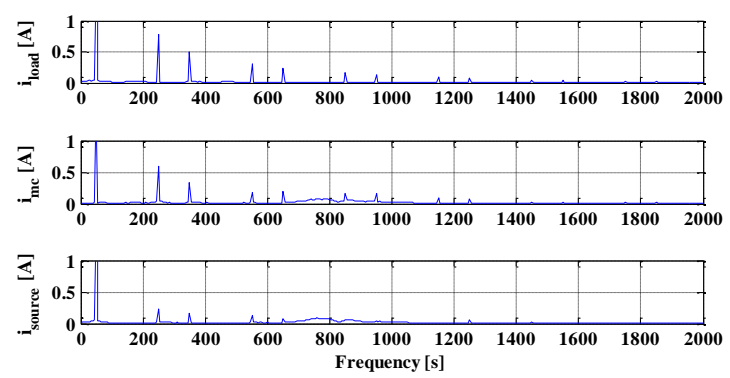

Fig. 10 Harmonic content of the load, matrix converter and source currents.

The first simulation was performed with unity power factor on the generator side. When the power factor is reduced to 0.6 , the THD of the source current can only be improved from $27 \%$ to $16.1 \%$. In figure 11 the source current has degraded compared to figure 9 . In figure 12 is represented the harmonic content of the load, matrix converter and source current. The harmonic content of the load is unchanged from the case of unity power factor which implies that the reference for the matrix converter current is the same except for the fundamental component that is reduced. However the current that the matrix converter injects into the grid has lower harmonic components. This leaves the source current with higher harmonic content than for the unity power factor case. In 
addition the content at resonance frequency is higher than the previous case indicating that the controller is not performing as well in reducing resonance effects.

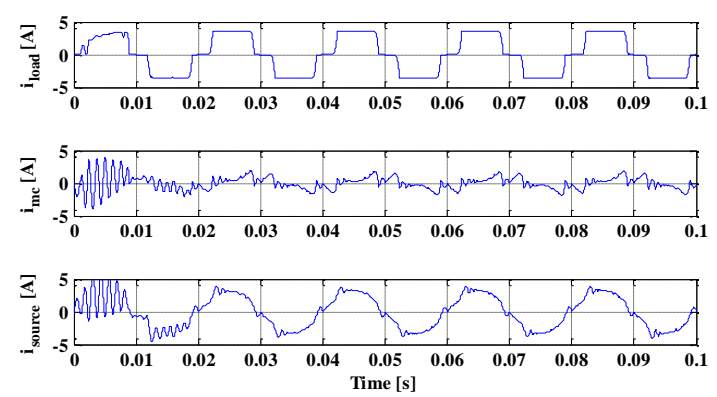

Fig. 11 load, matrix converter and source current for a power factor of 0.6 on the PM machine side.
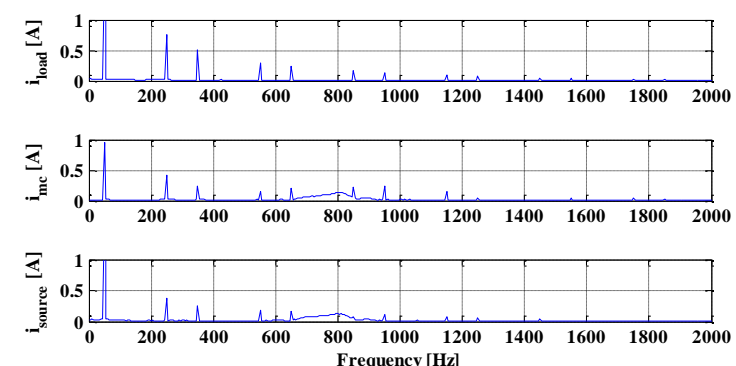

Fig. 12 Harmonic content of the load, matrix converter and source currents for a power factor of 0.6 on the PM machine side.

In figure 13 the THD of the source current is plotted as a function of the power factor of the PM machine side. The capability of the matrix converter to compensate for the load harmonics degrades when the power factor on the PM machine side is reduced.

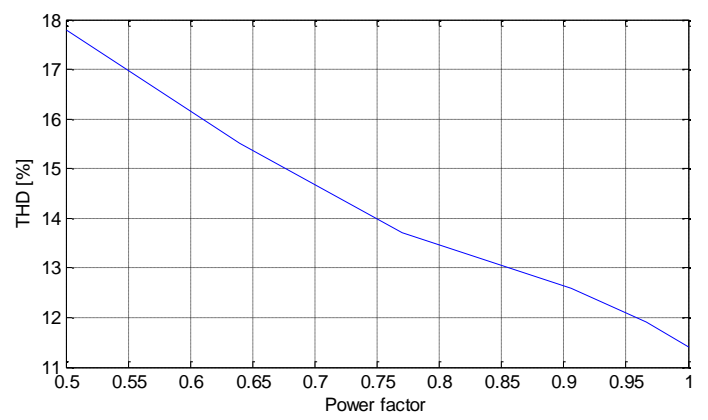

Fig. 13 THD of source current as a function of the power factor of PM machine.

The reason for the degradation at lower machine power factors is the indirect space vector modulation. To understand this it can be useful to turn to the IMC. The DC link current is a function of the generator side power factor. This can be easily seen by equating the input and output active powers.

$$
\begin{aligned}
& P_{d c}=i_{d c} \cdot e_{d c}=P_{\text {out }}=\frac{3}{2} \hat{V}_{\text {out }} \hat{I}_{\text {out }} \cos \Theta_{\text {out }} \\
& i_{d c}=\frac{\hat{V}_{\text {out }} \hat{I}_{\text {out }} \cos \Theta_{\text {out }}}{\hat{V}_{\text {in }} \cos \Theta_{\text {in }}}
\end{aligned}
$$

When the machine side power factor is reduced, the virtual dc link current in a direct matrix converter is consequently reduced. Thus there is less current available to synthesize the desired input current [3], [6]. To resolve this problem other modulation schemes that have an extended current controllability can be employed like the modulation presented in [7]. Further work will be to improve the active filtering properties of the matrix converter by employing other modulation schemes.

\section{Conclusion}

In this paper was investigated the possibility to use the matrix converter interfacing a PM generator to provide active filtering. The simple indirect space vector modulation was employed. The filtering current injected by the matrix converter and the input filter capacitor voltage were successfully controlled by cascaded proportional control loops which managed to avoid resonance that can occur in LC filters. The matrix converter proved to be efficient for active filtering purposes, especially for high values of the generator side power factor. At lower power factor values the input current controllability of the matrix converter is reduced because of the modulation. Further work will be to evaluate whether other modulation techniques can improve the active filtering properties of the matrix converter.

\section{References}

[1] H. Akagi, E. H. Watanabe, M. Aredes, Instantaneous Power Theory and Applications to Power Conditioning, IEEE Press, Wiley-Interscience, 2007.

[2] B. Bahrani, G. Grinberg, "Investigation of Harmonic Filtering for the State-of-the-art Variable Speed Drives", in Proc. EPE 2009, pp. 1-10.

[3] J.-I. Itoh, S. Tamada, "A Novel Engine Generator System with Active Filter and UPS Functions Using a Matrix Converter”, in Proc. EPE 2007, pp. 1-10.

[4] A. Garcés, M. Molinas, "A Control Strategy for Series Connected Offshore Wind Turbines", in Proc. IEEE PEDS 2011.

[5] P. Wheeler, J. Rodriguez, J. Clare, L. Empringham, A. Weinstein, "Matrix Converters: A Technology Review", IEEE Trans. on Ind. Electr., vol. 49, pp. 276288, Apr. 2002.

[6] N. Holtsmark, M. Molinas, "Reactive power compensation capability of a matrix converter-based FACTS device", in Proc. IEEE Powertech 2011.

[7] F. Schafmeister, J. Kolar, "Novel Hybrid Modulation Schemes Significantly Extending the Reactive Power Control Range of All Matrix Converter Topologies with Low Computational Effort", IEEE Trans. on Ind. Electro., vol. 59 pp. 194-210, Jan. 2012. 